\title{
O rombo fictício das aposentadorias dos servidores
}

\section{The fictitious hole of public servants' pensions}

\author{
José Carlos de Oliveira \\ Departamento de Eletrotécnica (DEE), Escola Politécnica (POLI), Universidade Federal \\ do Rio de Janeiro (UFRJ) \\ Programa de Pós-Graduação em História das Ciências e das Técnicas e Epistemologia \\ (HCTE), Universidade Federal do Rio de Janeiro (UFRJ) \\ jcarlos@dee.ufrj.br \\ orcid.org/0000-0002-0415-4926

\section{José Miguel Bendrao Saldanha} \\ Departamento de Engenharia Industrial (DEI), Escola Politécnica (POLI), Universidade \\ Federal do Rio de Janeiro (UFRJ) \\ Doutorando do Programa de Pós-Graduação em História das Ciências e das Técnicas e \\ Epistemologia (HCTE), Universidade Federal do Rio de Janeiro (UFRJ) \\ zemig@poli.ufrj.br \\ orcid.org/0000-0002-4203-6461
}

Resumo. O discurso do "déficit previdenciário", pejorativamente apelidado de "rombo" para sugerir uma falha, um problema, um defeito, é antigo e acompanha as notícias sobre o financiamento da previdência social desde sempre, especialmente desde a promulgação da Constituição Federal de 1988, e tem sido o principal argumento para justificar medidas que reduzem valores pagos aos trabalhadores e dificultam-lhes o acesso aos benefícios. Na verdade, no que tange aos regimes próprios dos servidores, o "rombo" pode ser fixado em qualquer valor que se queira, porque é o resultado de operações contábeis baseadas em valores fictícios, definidos arbitrariamente por dispositivos legais que expressam escolhas políticas sem significado econômico.

Palavras-chave: Rombo da previdência dos servidores. Regime de repartição. Regime administrativo.

Abstract. The "social security deficit" discourse, pejoratively dubbed "hole" to suggest a flaw, a problem, a defect, is old and has been following the news about social security financing since forever, especially since the promulgation of the 1988 Federal Constitution, and it has been the main argument to justify measures 
that reduce amounts paid to workers and make it difficult for them to access benefits. In fact, as far as the public servants' regimes are concerned, the "hole" can be defined at any wanted amount, because it is the result of accounting operations based on fictitious values, arbitrarily defined by legal provisions that express political choices without economic meaning.

Keywords: Hole of public pensions. Pay-as-you-go system. Administrative system.

Recebido: 08/10/2018 Aceito: 28/10/2018 Publicado: 07/11/2018

\section{Introdução}

Na manhã do dia 22 de janeiro de 2018, o secretário de Previdência Marcelo Abi-Ramia Caetano apresentou em coletiva de imprensa os resultados do Regime Geral de Previdência Social (RGPS) e do Regime Próprio de Previdência Social da União (RPPS), relativos ao ano de 2017. Segundo o governo, o RGPS teve nesse ano um déficit de R\$ 182,4 bilhões, dos quais $\mathrm{R} \$ 71,7$ bilhões no setor urbano e $\mathrm{R} \$ 110,7$ bilhões no setor rural, e o RPPS um déficit de $\mathrm{R} \$ 86,3$ bilhões, sendo $\mathrm{R} \$ 45,2$ bilhões devidos aos servidores civis, $\mathrm{R} \$ 37,7$ bilhões aos militares e $\mathrm{R} \$ 3,4$ bilhões aos demais. ${ }^{1}$ Somando os déficits do RGPS e do RPPS, o governo encontrou então um déficit global na previdência social da União em 2017 igual a R\$268,8 bilhões. "O secretário da Previdência Social, Marcelo Caetano, destacou que tanto o déficit do INSS quanto o dos servidores públicos são recordes." (SIMÃO, 2018)

A grande imprensa nacional divulgou os resultados com alarde, como se vê, por exemplo, nas manchetes do dia seguinte, 23 de janeiro, da Folha de S. Paulo, na primeira página, "Previdência tem déficit recorde de R\$268,8 bi no ano de 2017"; d'O Globo, na primeira página, em letras garrafais, "Rombo histórico - Déficit da Previdência dispara e atinge $R \$ 268,7$ bi", e do Valor Econômico, na segunda página: "Rombo da Previdência Social aumenta 18,5\% e fecha 2017 em $R \$ 268,8$ bilhões".

Uma análise do Relatório Resumido de Execução Orçamentária do Governo Federal de dezembro de 2017 (MFSTN, 2017) revela que estes valores foram obtidos da forma que está consolidada no quadro 1 , a seguir.

\footnotetext{
${ }^{1}$ A apresentação do governo não esclarece o que seriam estes "demais". A Secretaria do Tesouro Nacional, fonte declarada dos dados apresentados, informa que houve em 2017 despesas de "Outros benefícios previdenciários" no valor de R \$ 1,675 bilhões e de "Demais despesas previdenciárias" no valor de R \$ 1,745 bilhões, ambas relativas a servidores civis, totalizando R \$ 3,420 bilhões (MFSTN, 2017, p.15-16). Neste estudo, foram incluídas nas despesas com aposentados e pensionistas civis.
} 
Quadro 1. Resultado do RPPS da União - 2017 (bilhões de reais)

\begin{tabular}{|l|r|r|r|}
\hline & \multicolumn{1}{|c|}{ Civis } & \multicolumn{1}{c|}{ Militares } & \multicolumn{1}{c|}{ Total } \\
\hline Contribuições recebidas & & & \\
\hline Ativos & 9,9 & 3,3 & 13,3 \\
\hline Aposentados e pensionistas & 3,8 & 0,0 & 3,8 \\
\hline Patronal (escritural, fictícia) + multas & 20,0 & 0,0 & 20,0 \\
\hline Total & 33,8 & 3,3 & 37,1 \\
\hline Benefícios pagos - total & 82,4 & 41,0 & 123,5 \\
\hline Resultado (déficit, "rombo") & 48,7 & 37,7 & 86,3 \\
\hline
\end{tabular}

Este discurso do "déficit previdenciário", pejorativamente apelidado de "rombo" para sugerir uma falha, um problema, um defeito, é antigo e acompanha as notícias sobre o financiamento da previdência social desde sempre, especialmente desde a promulgação da Constituição Federal de 1988. Tem sido o principal argumento para justificar contrarreformas $^{2}$ que, invariavelmente, reduzem valores pagos aos trabalhadores e dificultam-lhes o acesso aos benefícios. Mostraremos aqui que, ao contrário do que é amplamente divulgado pelos governos, pela grande imprensa e pelos empresários da "previdência" privada, esse "rombo" é o resultado de operações contábeis baseadas em valores fictícios, definidos arbitrariamente por dispositivos legais que expressam escolhas políticas sem significado econômico. Para isso, é preciso conhecer um pouco da história recente da previdência dos servidores públicos e das transformações ocorridas nos regimes de financiamento das suas aposentadorias.

\section{A Constituição Federal de 1988}

A Constituição Federal de 1988 (CF 88) consolidou regras e conceitos diferentes, a partir de disposições já existentes, para as aposentadorias dos trabalhadores do setor privado e dos servidores públicos. A aposentadoria dos trabalhadores do setor privado foi definida como um benefício do regime geral de previdência social (RGPS), no âmbito da organização da seguridade social, enquanto a aposentadoria dos servidores públicos civis foi tratada na organização da administração pública. As regras para os militares foram remetidas à lei ordinária. ${ }^{3}$

Tanto o regime geral quanto o dos servidores civis concediam aposentadoria aos homens com 65 anos de idade ou 35 anos de trabalho e às mulheres com 60 anos de idade ou 30 anos de trabalho. Professores e professoras, de qualquer nível, aposentavam-se com menos 5 anos de trabalho. $\mathrm{O}$ valor da aposentadoria, contudo, não era o mesmo nos dois

\footnotetext{
${ }^{2}$ Os proponentes não as chamam assim. Para eles, são "reformas". Optei pelo termo contrarreformas, por não ser possível atribuir-lhes a habitual conotação positiva dada pela palavra "reforma".

${ }^{3} \mathrm{O}$ leque de benefícios da previdência social é muito amplo. Aqui trataremos apenas de aposentadorias e pensões.
} 
regimes. Os servidores mantinham a remuneração do cargo que ocupavam na atividade (integralidade), inclusive acompanhando os reajustes e reclassificações posteriores dos servidores ativos (paridade), enquanto os trabalhadores do setor privado recebiam a média dos 36 últimos salários de contribuição, que depois era reajustada de acordo com a inflação. As formas de cálculo das duas regras não resultavam em valores semelhantes, porque no regime geral havia, e ainda há, um limite máximo para o salário de contribuição e para as aposentadorias, hoje no valor de $\mathrm{R} \$ 5.645,81$, enquanto para os servidores o único limite era o de um servidor na ativa, hoje igual a $\mathrm{R} \$ 33.763,00$. Outra diferença era a aposentadoria compulsória aos 70 anos de idade no serviço público, atualmente fixada em 75 anos.

A principal diferença conceitual entre os dois regimes estava, no entanto, na origem dos recursos para o pagamento das aposentadorias, ou seja, nos seus regimes de financiamento $^{4}$.

Pelo RGPS, o direito aos benefícios tinha como condição explícita a contribuição dos segurados, mas esta não seria a única fonte de recursos do regime, uma vez que as aposentadorias, bem como as demais despesas da seguridade social, deveriam ser pagas pelos governos, pelos trabalhadores e pelos empregadores, as destes calculadas sobre a folha de salários, o faturamento e o lucro, tudo com base na "diversidade da base de financiamento" e outros critérios. Logo, embora operando pelo regime de repartição, o RGPS não o faria de forma "pura", e sim integrada ao financiamento geral da seguridade social.

Por outro lado, as aposentadorias dos servidores foram definidas simplesmente como uma obrigação do Estado. Nenhuma contribuição se exigia dos servidores para terem direito à aposentadoria, nem havia fonte de recursos específica para o pagamento das aposentadorias $^{5}$, que deveriam então ser mantidas da mesma forma que os vencimentos dos servidores ativos e todos os demais gastos governamentais, ou seja, pelas receitas gerais de impostos, contribuições etc do Estado. As aposentadorias dos servidores financiavam-se integralmente, por um regime administrativo, de forma coerente com a ideia, materializada no capítulo da administração pública da CF 88, de definir um corpo estável de funcionários públicos dotados de um conjunto de direitos e deveres compatíveis com as necessidades de um Estado social.

\section{A CF 88 freada pelo avanço neoliberal}

A CF 88 foi produzida na esteira do fim da ditadura empresarial-militar brasileira (19641985), numa fase de relativa ascensão dos movimentos sociais, e caracterizou-se pela

\footnotetext{
${ }^{4} \mathrm{O}$ termo "regime" tem sido usado, na legislação e na linguagem comum relativa à previdência social, com pelo menos dois significados diferentes: ora se refere a conjuntos articulados de direitos e deveres (RJU, RGPS etc), ora nomeia formas de financiamento de sistemas de previdência (regime de repartição, regime de capitalização). Tentando evitar confusões, neste texto chamaremos estes de "regimes de financiamento". ${ }^{5}$ A contribuição que os servidores ativos faziam até então destinava-se ao custeio da saúde e das pensões.
} 
consolidação de alguns importantes direitos sociais, de forma, contudo, contraditória à ascensão do neoliberalismo já em curso naquela época em escala mundial. Os constituintes representantes das forças conservadoras organizaram-se no chamado "centrão" e conseguiram impedir avanços mais expressivos e condicionar a vigência de muitos daqueles direitos à sua regulamentação posterior por meio de leis ordinárias ou complementares. Os retrocessos nas conquistas da classe trabalhadora brasileira não demoraram a acontecer, nas regulamentações e em emendas à própria CF 88, praticamente todas na direção da retirada de direitos dos trabalhadores e ampliação dos direitos do capital, alinhando-se assim às transformações semelhantes que ocorriam no resto do mundo. Dentre as principais mudanças, destacam-se as referentes à administração pública e à previdência social, as chamadas "reforma administrativa" e "reforma da previdência". A contrarreforma da previdência inspirou-se claramente nas recomendações do Banco Mundial expressas no seu relatório Evitando a Crise da Velhice, de $1994^{6}$, aplicadas apenas parcialmente. De uma forma geral, podem identificarse duas fases da contrarreforma da previdência brasileira pós - CF 88, conceitualmente relacionadas e politicamente articuladas, a primeira durante os governos Collor, Franco e Cardoso, e a segunda durante os governos Lula da Silva e Dilma Roussef.

A Emenda Constitucional $\mathrm{n}^{\mathrm{o}}$ 20, de 15/12/1998 (EC 20), conduzida pelo governo Fernando Henrique Cardoso, constitui o núcleo da $1^{\text {a }}$ fase. Nela, o conceito de "tempo de serviço", do regime dos servidores, e o de "tempo de trabalho", do regime geral, foram substituídos pelo de "tempo de contribuição". O trabalhador deixou de ter direito à aposentadoria por ter trabalhado (ou servido ao público), passando a tê-lo por ter contribuído financeiramente. De um direito do trabalho, a aposentadoria transformou-se num direito financeiro. Entre outras consequências, isto ajudou a nutrir a ilusão de que cada trabalhador é responsável pela sua própria aposentadoria e que é possível prescindir da solidariedade entre as gerações que necessariamente sustenta todo o sistema.

A EC 20 também obrigou ambos os regimes ao "caráter contributivo" e ao "equilíbrio financeiro e atuarial"7. A participação dos servidores ativos no custeio do regime de previdência já havia sido instituída pela Emenda Constitucional no 3, de 17/3/1993 (EC 3), durante o governo Itamar Franco, mas não o "equilíbrio financeiro e atuarial". Tentativas anteriores de criar essa contribuição haviam sido anuladas pelo Supremo Tribunal Federal (STF), justamente por não terem base constitucional, empecilho removido pela aprovação da EC 3.

No caso dos Regimes Próprios de Previdência Social (RPPS's), como passaram a ser chamados os regimes dos servidores civis, a consequência imediata da aplicação dos critérios contributivo e de equilíbrio, aparentemente repletos da mais pura sensatez, foi a transformação do seu regime de financiamento, que deixou de ser administrativo e passou

\footnotetext{
${ }^{6}$ THE WORLD BANK (1994).

7 O "equilíbrio atuarial" obtém-se quando os valores dos fluxos previstos de receitas e despesas, descontados por meio de uma taxa de juros de referência, são iguais. Depende, portanto, do valor arbitrado para essa taxa por quem faz as contas.
} 
abruptamente a ser de repartição. Assim o Estado "transferiu" instantaneamente para os servidores civis ativos parte da responsabilidade, até então totalmente sua, de sustentar os servidores aposentados. Na prática, o sistema continuou a ser mantido pelo Estado, pois os recursos economizados com a redução das remunerações líquidas dos servidores ativos jamais foram suficientes para pagar as despesas com os aposentados, mesmo considerando a "auto contribuição" fictícia do governo ${ }^{8}$. Uma das razões óbvias deste "desequilíbrio" é a existência de uma grande quantidade de servidores aposentados e de pensionistas em relação à quantidade de servidores ativos. Esta operação legislativa fez todos os RPPS's (da União, dos estados e dos municípios) exibirem déficits orçamentários gigantescos, que passaram a ser sistematicamente usados pelos defensores do aprofundamento da contrarreforma como argumentos a favor de mais cortes de direitos dos servidores. Um resumo das contas do RPPS da União de 2014 a 2017, por exemplo, na forma como são apresentadas nos documentos oficiais, pode ser visto no quadro 2 a seguir.

\section{Quadro 2. Resultado do RPPS da União de 2014 a 2017}

(Bilhões de reais de dezembro de 2017, corrigidos pelo INPC do IBGE)

\begin{tabular}{|c|c|c|c|c|}
\hline & 2014 & 2015 & 2016 & 2017 \\
\hline Receitas de "contribuições" & 35,4 & 35,0 & 34,3 & 37,1 \\
\hline Ativos & 12,8 & 12,6 & 12,5 & 13,3 \\
\hline civis & 10,0 & 9,7 & 9,5 & 9,9 \\
\hline militares & 2,8 & 2,9 & 3,0 & 3,3 \\
\hline Aposentados e pensionistas & 3,3 & 3,3 & 3,2 & 3,8 \\
\hline civis & 3,3 & 3,3 & 3,2 & 3,8 \\
\hline Patronal (fictícia) + multas & 19,4 & 19,1 & 18,6 & 20,0 \\
\hline Despesas de proventos, pensões e reformas & 116,5 & 113,9 & 113,1 & 123,5 \\
\hline civis & 77,9 & 75,6 & 75,3 & 82,4 \\
\hline militares & 38,6 & 38,2 & 37,8 & 41,0 \\
\hline Déficit ("rombo") previdenciário fictício & $-81,0$ & $-78,9$ & $-78,7$ & $-86,3$ \\
\hline civis & $-45,3$ & $-43,5$ & $-44,0$ & $-48,7$ \\
\hline militares & $-35,7$ & $-35,4$ & $-34,8$ & $-37,7$ \\
\hline
\end{tabular}

Fonte: Elaboração própria, a partir dos RREO do Governo Federal dos anos de 2014 a 2017.

\section{Contabilizações fictícia e real do RPPS da União}

Antes de mais nada, registremos o fato óbvio de que, em última instância, todos os gastos da União com os servidores ativos e aposentados, civis ou militares, e respectivos

\footnotetext{
${ }^{8}$ Ver a linha "Patronal (escritural, fictícia) + multas " no Quadro 1 deste texto.
} 
pensionistas são pagos pela arrecadação geral do Estado. Esses gastos incluem tanto os ganhos líquidos dos servidores ativos quanto as suas "contribuições" (que são descontadas dos seus contracheques) que são contabilizadas como "receitas" do RPPS que "ajudarão a pagar" os ganhos dos aposentados e pensionistas. Estas "contribuições" são, portanto, na verdade, reduções nos vencimentos dos ativos, que, se não existissem, não comprometeriam em absolutamente nada o pagamento dos aposentados e pensionistas, que teriam simplesmente uma parcela maior a ser paga diretamente pela União. Esta responsabilidade da União está expressa no parágrafo único do artigo $8^{\circ}$ na Lei 10.887/04, que trata também da "contribuição patronal", que analisaremos a seguir:

\footnotetext{
"Art. $8^{\circ}$ A contribuição da União, de suas autarquias e fundações para o custeio do regime de previdência, de que trata o art. 40 da Constituição Federal, será o dobro da contribuição do servidor ativo, devendo o produto de sua arrecadação ser contabilizado em conta específica.

Parágrafo único. A União é responsável pela cobertura de eventuais insuficiências financeiras do regime decorrentes do pagamento de benefícios previdenciários." (BRASIL, 2004)
}

O caput do artigo define que o valor da contribuição patronal é igual ao dobro da "contribuição" do servidor ativo (quer dizer, do desconto que reduziu o seu valor líquido) e o parágrafo único garante o "equilíbrio atuarial e financeiro" introduzido na Constituição pela EC 20. O caput representa a "contribuição patronal" e o parágrafo único representa o déficit previdenciário, pejorativamente denominado de "rombo".

O artigo, no seu conjunto, define, portanto, qual será a contribuição total da União para o custeio dos aposentados e pensionistas. É evidente que a divisão desta contribuição em "contribuição patronal" e "rombo" depende do valor arbitrado pela Lei para aquela. Se a redação do caput for modificada, por exemplo, para que a contribuição passe a ser o quádruplo da contribuição do servidor, o déficit será automaticamente reduzido, sem que haja qualquer aumento na despesa do Estado!

Levando em conta estas reflexões, vejamos como contabilizar as folhas de pagamento dos ativos, aposentados e pensionistas da União, de forma a ficar mais claro o que de fato acontece. O quadro 3, a seguir, apresenta os valores efetivamente pagos (líquidos) aos servidores ativos, aposentados e pensionistas, civis e militares, entre 2014 e 2017. Não é demais destacar que estes valores representam o custo efetivo dos servidores $e$ pensionistas para a União, independentemente dos nomes que se lhes dê. 
Quadro 3. Folha de pagamento da União, valores efetivamente pagos

(Bilhões de reais de dezembro de 2017, corrigidos pelo INPC do IBGE)

\begin{tabular}{|c|r|r|r|r|}
\hline & \multicolumn{1}{|c|}{2014} & \multicolumn{1}{|c|}{2015} & \multicolumn{1}{|c|}{2016} & \multicolumn{1}{c|}{2017} \\
\hline Gastos efetivos com ativos & 139,1 & 135,1 & 135,6 & 147,5 \\
\hline civis & 116,5 & 112,4 & 113,9 & 124,9 \\
\hline militares & 22,6 & 22,7 & 21,7 & 22,6 \\
\hline $\begin{array}{l}\text { Gastos efetivos com aposentados e } \\
\text { pensionistas }\end{array}$ & 113,2 & 110,6 & 109,8 & 119,6 \\
\hline civis & 74,7 & 72,3 & 72,1 & 78,6 \\
\hline militares & 38,6 & 38,2 & 37,8 & 41,0 \\
\hline Gastos efetivos totais & 252,4 & 245,7 & 245,4 & 267,2 \\
\hline civis & 191,2 & 184,8 & 185,9 & 203,5 \\
\hline militares & 61,2 & 60,9 & 59,5 & 63,6 \\
\hline
\end{tabular}

Fonte: Elaboração própria, a partir dos RREO do Governo Federal dos anos de 2014 a 2017

\section{Conclusões}

O quadro 2 representa, portanto, uma contabilização fictícia do RPPS e o quadro 3 uma contabilização real da folha de pagamento completa da União. Da comparação entre os dois, vemos (quadro 4, a seguir) que, mantida a redação do caput do artigo $8^{\circ}$ da Lei 10.887, a despesa total da União com os seus servidores e pensionistas compõe-se de uma parte chamada "rombo" e outra parte que não é chamada rombo.

\section{Quadro 4. Composição da despesa de pessoal da União em "rombo" e "não- rombo"}

(Bilhões de reais de dezembro de 2017, corrigidos pelo INPC do IBGE)

\begin{tabular}{|l|r|r|r|r|}
\hline & \multicolumn{1}{|c|}{2014} & \multicolumn{1}{|c|}{2015} & \multicolumn{1}{c|}{2016} & \multicolumn{1}{c|}{2017} \\
\hline Gasto com pessoal que "não é rombo" [A] & 171,3 & 166,8 & 166,7 & 180,8 \\
\hline Déficit previdenciário ("rombo") [B] & 81,0 & 78,9 & 78,7 & 86,3 \\
\hline Gastos efetivos totais [A] + [B] & 252,4 & 245,7 & 245,4 & 267,2 \\
\hline
\end{tabular}

Fonte: Elaboração própria, a partir dos RREO do Governo Federal dos anos de 2014 a 2017

Vemos, portanto, que o tamanho do "rombo" pode ser fixado no valor que se quiser, bastando para isso definir convenientemente o cálculo da "contribuição patronal" na Lei. 


\section{Referências}

BRASIL. Lei $\mathbf{n}^{\mathbf{0}} \mathbf{1 0 . 8 8 7}$, de 18 de junho de 2004. Dispõe sobre a aplicação de disposições da Emenda Constitucional $\mathrm{n}^{\circ}$ 41, de 19 de dezembro de 2003. Disponível em http://www.planalto.gov.br/ccivil_03/_Ato2004-2006/2004/Lei/L10.887.htm. Acesso em: 20 de dezembro de 2016.

MINISTÉRIO DA FAZENDA - SECRETARIA DO TESOURO NACIONAL (MFSTN). RREO - Relatório resumido de execução orçamentária do governo federal e outros demonstrativos. Brasília: Ministério da Fazenda, dezembro de 2014.

MINISTÉRIO DA FAZENDA - SECRETARIA DO TESOURO NACIONAL (MFSTN). RREO - Relatório resumido de execução orçamentária do governo federal e outros demonstrativos. Brasília: Ministério da Fazenda, dezembro de 2015.

MINISTÉRIO DA FAZENDA - SECRETARIA DO TESOURO NACIONAL (MFSTN). RREO - Relatório resumido de execução orçamentária do governo federal e outros demonstrativos. Brasília: Ministério da Fazenda, dezembro de 2016.

MINISTÉRIO DA FAZENDA - SECRETARIA DO TESOURO NACIONAL (MFSTN). RREO - Relatório resumido de execução orçamentária do governo federal e outros demonstrativos. Brasília: Ministério da Fazenda, dezembro de 2017.

MINISTÉRIO DA FAZENDA - SECRETARIA DE PREVIDÊNCIA (MFSP). Resultado do Regime Geral de Previdência Social - RGPS 2017. Brasília: Ministério da Fazenda, janeiro de 2018.

SIMÃO, E. Déficit da Previdência aumenta para R $\$ 268,8$ bilhões em 2017. Valor Econômico, São Paulo, 22 jan. 2018. Disponível em http://www.valor.com.br/brasil/5272353/deficit-da-previdencia-aumenta-parar-2688-bilhoes-em-2017\#. Acesso em: 23 jan. 2018.

THE WORLD BANK. Averting the Old Age Crisis: Policies to Protect the Old and Promote Growth. New York: Oxford University Press, 1994. 